\title{
Grandes projetos de investimentos em Itaguaí-RJ e investimentos em educação: o dilema do desenvolvimento territorial ${ }^{1}$
}

\author{
Lamounier Erthal Villela \\ Programa de Pós-Graduação em Desenvolvimento Territorial e Políticas Públicas da Universidade Federal Rural do \\ Rio de Janeiro (Ufrrj) \\ Marcelo de Oliveira Vidal \\ Pós-doutorando do Programa de Pós-Graduação em Desenvolvimento Territorial e Políticas Públicas da \\ Universidade Federal Rural do Rio de Janeiro (Ufrrj)
}

Recebido: 04/09/2014 Versão revisada (entregue): 19/09/2014 Aprovado: 23/09/2014

\begin{abstract}
Resumo
Segundo a Federação das Indústrias do Estado do Rio de Janeiro, o munícipio de Itaguaí concentra uma grande parte dos megaempreendimentos em andamento no estado do Rio de Janeiro. Neste contexto, destacam-se os projetos da indústria naval e portuária, que contribuem significativamente para o aumento das receitas fiscais do município. Objetiva-se neste artigo verificar como se dão os investimentos municipais em educação no momento em que o crescimento econômico se dá de forma tão acelerada. Questiona-se, então, se este crescimento estaria se traduzindo no aumento das inversões em educação e, consequentemente, na melhoria da qualidade de vida da população local. Através de dados sobre as transformações estruturais em andamento no local, conclui-se que os indicadores de desenvolvimento socioeconômico e educacionais não acompanham o ritmo dos investimentos locais, criando assim um hiato entre crescimento e desenvolvimento local.
\end{abstract}

Palavras-chave | Crescimento econômico; desenvolvimento territorial; educação; gestão social; governança; grandes projetos de investimento.

Código JEL | H52; I25; R58.

${ }^{1}$ Uma versão inicial deste artigo foi apresentada no II SEDRES, no GT Estado, Planejamento e Politicas Públicas de Desenvolvimento Regional, que ocorreu em Campina Grande (PB) entre 13 e 15 de agosto de 2014. 


\title{
MAJOR INVESTMENT PROJECTS IN ITAGUAÍ-RJ AND INVESTMENTS IN EDUCATION: THE DILEMMA OF TERRITORIAL DEVELOPMENT
}

\begin{abstract}
According to the Federation of Industries of the State of Rio de Janeiro, the municipality of Itaguaí focuses a large part of the ongoing mega-projects in the State of Rio de Janeiro. In this context, the projects of the naval and port industry have prominence because they contribute significantly to the increase in tax revenues of the municipality. The aim of this article is to analyze how municipal investments in education are made at the time when the growth of the local economy has accelerated. We question, then, whether this growth would be translating in increased investments in education and, consequently, improving the quality of life of local people. Using data about the structural changes underway in Itaguaí, we conclude that the indicators of socioeconomic and educational development do not keep pace with local investments, thus creating a gap between growth and local development.
\end{abstract}

Keywords | Economic growth; education; governance; large investment projects; social management; territorial development.

JEL-Code | H52; I25; R58.

\section{GRANDES PROYECTOS DE INVERSIÓN EN ITAGUAÍ-RJ E INVERSIONES EN LA EDUCACIÓN: EL DILEMA DE DESARROLLO TERRITORIAL}

\section{Resumen}

De acuerdo con la Federación de Industrias del Estado de Rio de Janeiro, el municipio de Itaguaí concentra gran parte de los mega-proyectos en curso en el Estado de Río de Janeiro. En este contexto se destacan los proyetos de la industria naval y portuária, los cuales contribuyen de manera significativa al aumento de los ingresos fiscales del municipio. El objetivo de este artículo es examinar cómo se dan las inversiones municipales en materia de educación en el momento en que el crecimiento económico se produce tan rápidamente. Es cuestionado si este crecimiento se está traduciendo en una mayor inversión en educación y, en consecuencia, en la mejora de la calidad de vida de la población local. Utilizando datos sobre los cambios estructurales en curso en el municipio de Itaguaí, se concluye que los indicadores de desarrollo socioeconómico y educativo no siguen el ritmo de las inversiones locales, creando así una brecha entre el crecimiento y el desarrollo local.

Palabras-clave | Crecimiento económico; desarrollo territorial; educación; gestión social; gobernanza; grandes proyectos de inversión.

Código JEL | H52; I25; R58.

\section{Introdução}

Segundo a FIRJAN (2014), o Rio de Janeiro recebeu de 2011 a 2013 investimentos públicos e privados que somaram 181,4 bilhões de reais. Comparado com a dimensão territorial do estado (43,7 mil km2), o volume do investimento é de mais de R\$ 4 milhões por quilômetro quadrado, fazendo do Rio o maior concentrador 
de investimentos do mundo. No caso de Itaguaí, entre outros muitos investimentos, está sendo desenvolvido um projeto entre Petrobras, CSN e Gerdau para construção de um porto compartilhado, onde será implantada a base de apoio da Petrobras à exploração do Pré-Sal. Itaguaí teve aumento expressivo no número de empregos criados principalmente nessa fase inicial de construção dos polos, mas estes não serão futuramente mantidos. Depois das obras terminadas, eles serão substituídos por outros que exigem diferentes qualificações profissionais. Desta forma, para que os Grandes Projetos de Investimentos (GPIs) se tornem propulsores do desenvolvimento são necessárias políticas públicas includentes, ou seja, que pensem na formação e capacitação da população local, permitindo assim um processo de inclusão social, local e regional. Neste sentido, a literatura sobre Desenvolvimento Territorial Sustentável nos alerta sobre a importância da coesão social, territorial e governabilidade, pois o desmantelamento do tecido social e da identidade local podem trazer efeitos perversos para a dinâmica regional (VILLELA et al., 2012).

O aumento expressivo da receita do município de Itaguaí em função da arrecadação proveniente dos GPIs abre, em uma primeira análise, a possibilidade de que sejam planejadas iniciativas do poder público que visem minimizar os impactos negativos dos GPIs e promover a qualidade de vida da população através da melhoria de serviços públicos, como a educação.

Desta forma, este artigo busca verificar o aumento das receitas do município entre os anos 2011 e 2013 e a evolução do sistema educacional neste período. Parte-se do pressuposto de que a educação é prioritária para o Desenvolvimento Territorial Sustentável. A educação emancipa o cidadão e torna-o mais apto a participar dos processos decisórios locais.

Para desenvolver o artigo iremos utilizar os seguintes aportes teóricos: os conceitos de GPI (VAINER, 2001) e suas imbricações entre gestão social, controle social (TENÓRIO, 2008a; 2008b), controle social e desenvolvimento territorial sustentável (PERICO, 2009). Os aspectos metodológicos buscaram a aplicação da teoria na prática seguindo um viés de análise crítica, para tal foram elaboradas: pesquisa bibliográfica, tematizada, documental e de campo. As pesquisas contribuíram para mapear as ações dos poderes públicos (Municipal, Estadual, Federal) no município de Itaguaí. Foram tratados dados obtidos no IBGE, Instituto Estadual do Ambiente [Inea], Prefeitura e Câmara de Itaguaí, Tesouro Nacional, FIRJAN e Ipeadata. Também foram feitas diversas incursões no campo para elaboração de entrevistas junto a representantes dos poderes públicos locais e conselheiros municipais, depoimentos e participação do grupo de

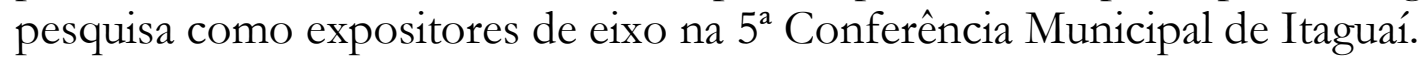




\section{Investimentos na Educação em Itaguaí: o contraste entre a receita do município e as realizações na área}

Para verificar os indicadores da política educacional no município de Itaguaí vis-àvis as questões relacionadas ao aumento populacional e uso dos recursos públicos, foram pesquisados dados que demostram o aumento da receita pública municipal e os dados sobre a educação.

Dentre os investimentos que ampliaram as receitas municipais destacam-se: a ampliação do Porto de Itaguaí, com a realização de obras de ampliação da área de manobra do porto; a duplicação da rodovia BR-101, no trecho entre a cidade do Rio de Janeiro e o distrito de Itacuruçá; a construção do Arco Metropolitano, com uma extensão de 145 quilômetros, ligando o complexo petroquímico da Petrobras em Itaboraí, chamado Complexo Petroquímico do Rio de Janeiro (COMPERJ), ao porto de Itaguaí; a construção da siderúrgica da Thiessen-Krupp Companhia Siderúrgica do Atlântico (TKCSA) na divisa com o município e o estaleiro da marinha para a construção dos submarinos nucleares. Na análise de Bueno (2009), esse conjunto de projetos é o maior investimento do setor privado no Brasil no momento, o que chama a atenção para o aumento das receitas no município e a janela de oportunidades para a inversão dessas receitas em serviços públicos de qualidade.

O Gráfico 1 mostra o aumento da renda própria do município. O Índice Firjan de Gestão Fiscal (IFGF) mostra os ganhos de receita que o município teve em função dos GPIs. As variáveis que compõem o índice incluem receita própria $(22,5 \%)$, gasto com pessoal $(22,5 \%)$, investimentos $(22,5 \%)$, liquidez $(22,5 \%)$ e custo da dívida (10\%). O indicador Receita Própria mede a capacidade de arrecadação de cada município e sua dependência das transferências de recursos dos governos estadual e federal. A média de Itaguaí para o período de 2006 a 2011 foi de 0,8795 , o que significa que o município, a princípio, teria grande autonomia para fazer políticas públicas abrangentes. 


\section{Gráfico 1 - Índice Firjan de Gestão Fiscal, Receita Própria}

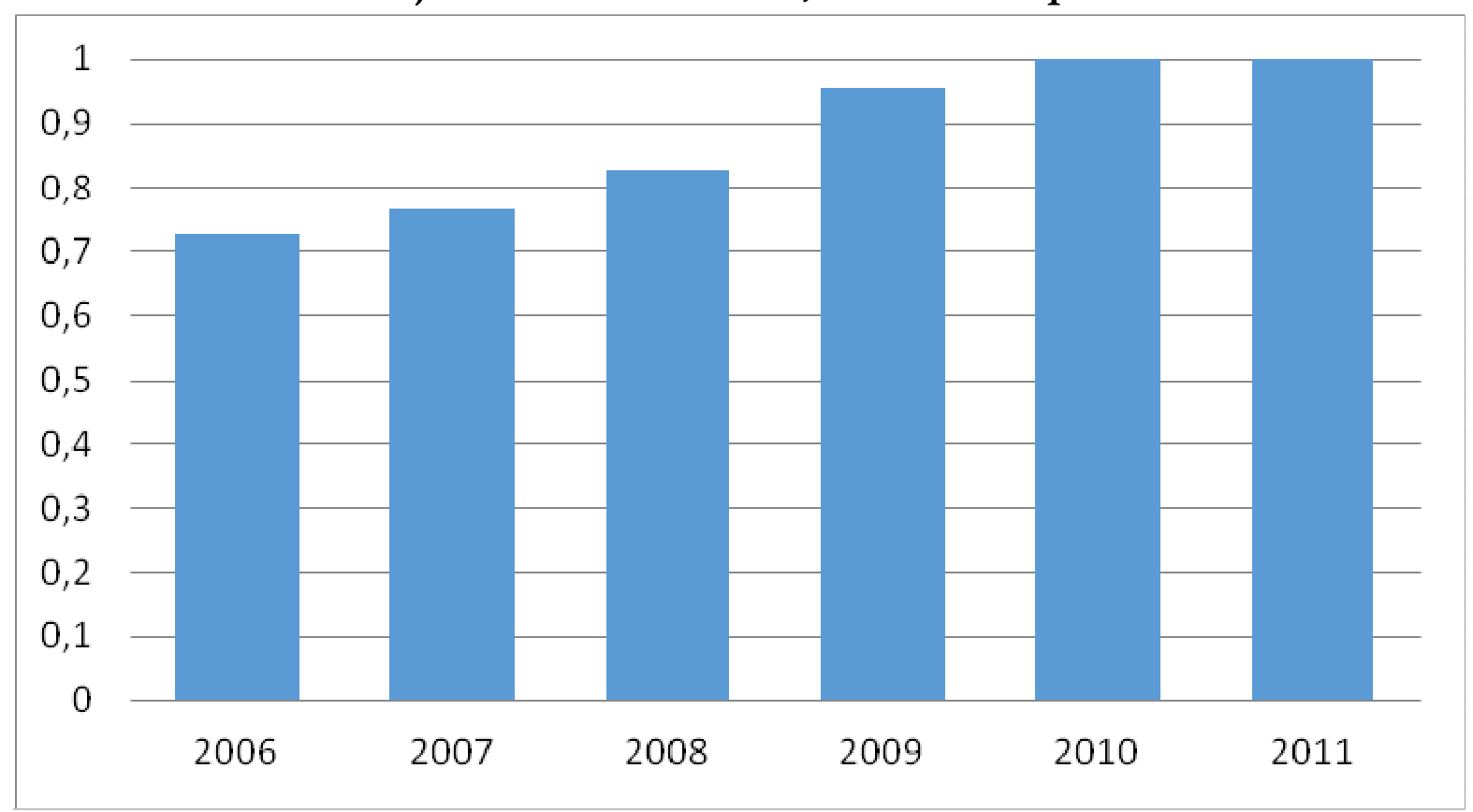

Fonte: Firjan (2014).

Ao mesmo tempo em que as receitas próprias crescem significativamente entre 2006 e 2011, como é possível observar no Gráfico 1, a composição das receitas constitucionais também cresce, num movimento que acontece em nível nacional e reflete uma melhora relativa na educação do país. A singularidade de possuir investimentos dos GPIs da ordem de bilhões, no entanto, não traz benefícios adicionais à cidade, como será possível perceber.

No Gráfico 2 observa-se que as transferências constitucionais crescem de cerca de 10 milhões de reais em 2004 para 60 milhões em 2013.

\section{Gráfico 2 - Composição das transferências constitucionais}

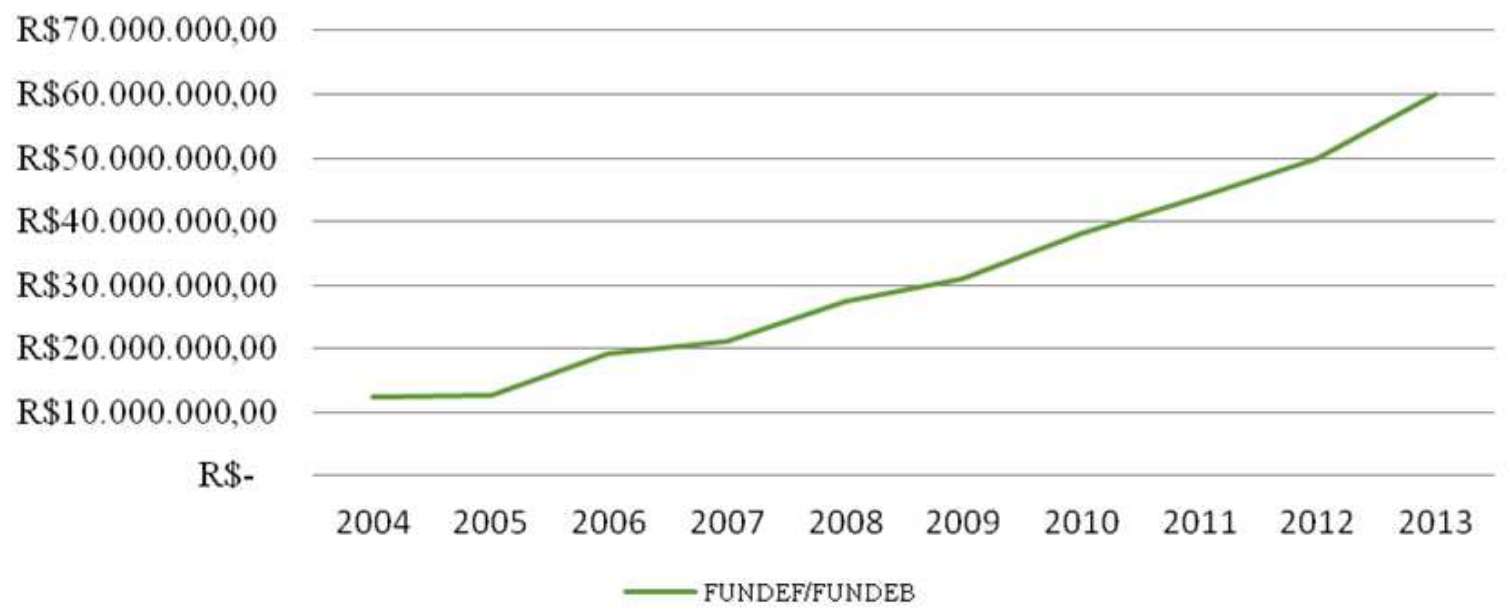

Fonte: Compilado a partir de Prefeitura (2014). 
Em função dos GPIs, observa-se um acelerado crescimento populacional e a consequente necessidade de ampliar a rede de ensino municipal. No Gráfico 3 observa-se um crescimento do número de habitantes a partir dos anos 2000, período no qual o número de pessoas vivendo na cidade vai de 82.003 para 115.542 em 2013 (IBGE, 2014).

\section{Gráfico 3 - Crescimento populacional de Itaguaí, 1999-2013}

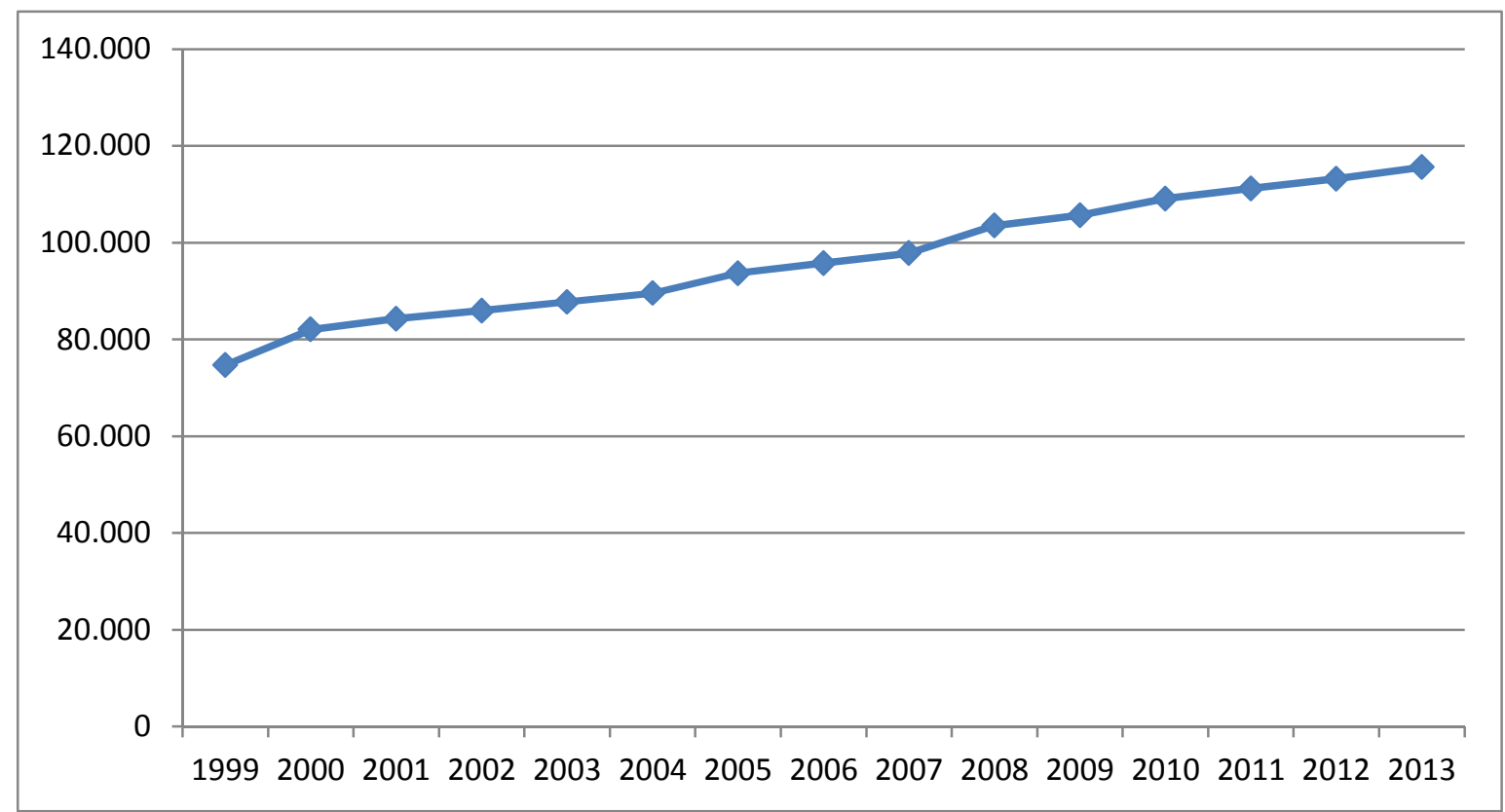

* 2013, estimativa do IBGE.

Fonte: Compilado a partir de IBGE (2014).

De outro lado, os gastos com educação apresentam uma queda de $24 \%$ no último ano, embora tenham crescido $96 \%$ no período de 2008 a 2013, em função principalmente do aumento das transferências constitucionais, cenário esse que se repete em grande parte do país. Dessa forma, é possível perceber que há um descolamento entre aumento da receita pública e melhoria da qualidade de vida da população local. 


\section{Gráfico 4 - Gastos com educação}

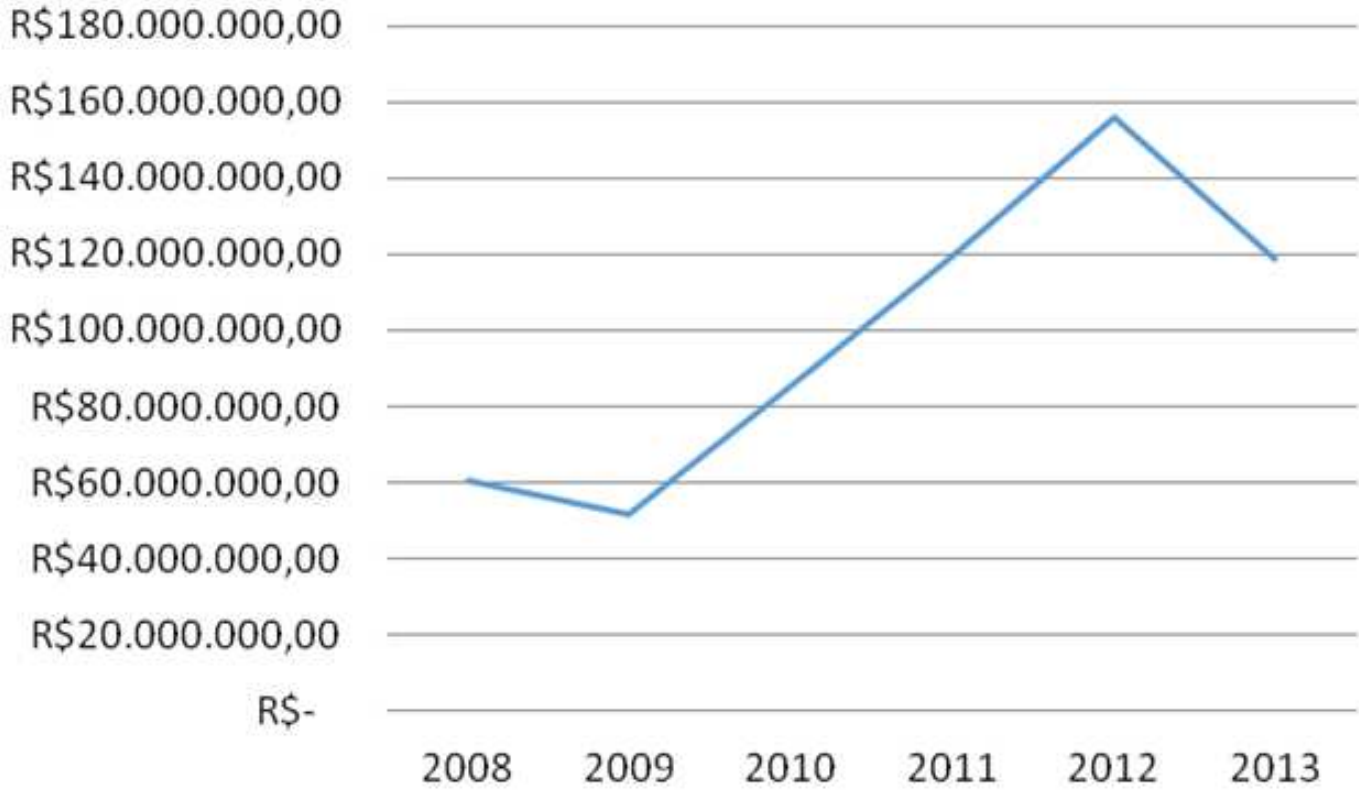

Fonte: Compilado a partir de Prefeitura (2014).

Verificou-se ainda que Itaguaí não conseguiu universalizar o acesso, pois 4,96\% das crianças de 5 a 6 anos ainda não ingressaram na escola. Esse cenário vai piorando na medida em que se acompanham os números das séries mais avançadas. Segundo o Atlas Brasil (2013), "a proporção de crianças e jovens frequentando ou tendo completado determinados ciclos indica a situação da educação entre a população em idade escolar do município e compõe o IDHM Educação". Verifica-se, neste caso, que a proporção de alunos cursando os diferentes módulos na idade recomendada vai decrescendo com o avançar dos ciclos escolares. Em 2010, em Itaguaí, apenas 9,42\% dos alunos de 18 a 24 anos estavam cursando o ensino superior; $23,95 \%$ dos jovens de 15 a 17 anos estavam cursando o ensino médio regular sem atraso; e 52,31\% dos alunos entre 6 e 14 anos estavam cursando o ensino fundamental regular. $O$ município apresenta algumas carências de equipamentos escolares nas várias esferas, principalmente no ensino superior, que é praticamente inexistente. Dessa forma, parte da população é obrigada a se deslocar para os municípios mais próximos Seropédica, Rio de Janeiro, Niterói e Volta Redonda, que oferecem campi universitários. Verificou-se que quase a totalidade dos gastos, 89,14\%, é direcionada ao Ensino Fundamental, já que Itaguaí não possui uma rede municipal de Ensino Médio.

Segundo o blog independente Política de Itaguaí, o município padece de falhas estruturais na infraestrutura que afetam inclusive as unidades construídas mais recentemente. Há tentativas de projetos de educação integral, mas a qualidade no tempo gasto na escola não se traduziria em qualidade de ensino. Uma cena muito comum nas unidades da rede, segundo o blog, é a fatídica virada de tempos, onde os professores da manhã dão lugar aos "oficineiros" do período da tarde. O 
improviso, segundo destacado nos blogs locais são prejudiciais ao projeto pedagógico de educação integral. Destacam-se também falhas na infraestrutura, pois existem computadores, mas não há acesso à internet. A Prefeitura de Itaguaí ainda não tem um projeto real de conexão permanente e rápida para as escolas.

No que se refere ao ensino fundamental de Itaguaí, responsabilidade do governo municipal, os dados denotam uma estagnação. Os indicadores avançam de forma tímida e regridem em alguns momentos. Entre 2005 e 2012, em detrimento do aumento populacional, houve uma queda real no número de professores (1.032 em 2005 para 904 em 2012) e de matrículas (15.589 em 2005 para 15.432 em 2012) e um aumento pequeno no número de unidades, de 33 para 38.

$\mathrm{Na}$ rede estadual a situação foi ainda mais grave. Reduziu-se o número de unidades (11 em 2005 para 9 em 2012), professores (308 em 2005 para 167 em 2012) e matrículas (5.023 em 2015 para 1.430 em 2012) no período de 2005 a 2012. Dessa forma, consolidou-se no período a competência municipal em relação à educação fundamental.

No que se refere ao ensino médio, o quadro de competências fica invertido, já que a única unidade municipal foi fechada em 2005. A partir desse período, a rede estadual passou a dividir exclusivamente com a iniciativa privada o número total de vagas disponíveis. Vale lembrar que, embora a competência do ensino médio seja predominantemente estadual, fica patente a falta de compromisso e de ousadia do poder público municipal na elaboração de políticas públicas que busquem oferecer serviços públicos educacionais à população local em todas as faixas etárias, visto que o crescimento da receita oriunda, principalmente dos GPIs, tende a proporcionar mudanças profundas na sociedade local. De qualquer forma, há uma elevação do número de concluintes do ensino médio. No período analisado destaca-se a criação do SENAI de Itaguaí, única iniciativa municipal de estimulo à educação profissionalizante que forma mão-de-obra necessária aos GPIs.

Na participação do grupo de pesquisa na V Conferência Nacional das Cidades e na Conferência Nacional de Meio Ambiente foi flagrante a reclamação dos conselheiros e cidadãos de Itaguaí sobre a qualidade da educação no município. Destacaram-se as falas sobre a falta de professores, falta de ensino profissionalizante e de nível superior para que a população local pudesse se inserir no novo mercado de trabalho em criação no município. Neste sentido, a literatura sobre Gestão Social coloca em evidência a necessidade da participação da sociedade nos processos de tomada de decisão e de controle social. Segundo Ferraz (2014), os conselheiros municipais de Itaguaí desconhecem o Plano Diretor, o PDDSMI, e não são chamados a acompanhar a direção das transformações em curso. Ao destacar a importância do poder local, Vainer (2001) desvela que os poderes públicos locais não estariam também capacitados para fazer frente a todas estas mudanças estruturais. Observa-se então uma hegemonia 
das forças de mercado (GPIs) sobre a sociedade e os poderes públicos locais. Ciente desta realidade, o BIRD (Banco Interamericano de Desenvolvimento) encomenda um plano de desenvolvimento sustentável para a Baia de Sepetiba, onde o foco maior são os investimentos no município de Itaguaí. Os relatórios intermediários destacam diversos problemas estruturais para uma dinâmica sustentável, porém, suas características tecnocráticas não contribuíram para instrumentalizar nem a sociedade local, nem os poderes públicos, muito menos os investidores. Assim, tem-se um quadro que ainda poderia ser revertido, mas que aponta problemas de sustentabilidade no longo prazo.

\section{Considerações finais}

O presente artigo buscou analisar como os Grandes Projetos de Investimento (GPI) no município de Itaguaí vêm transformando a realidade local e como os indicadores da educação podem elucidar a lógica de transformação em curso. Observou-se, ao longo deste artigo, que houve um aumento significativo da arrecadação fiscal municipal e das inversões públicas em educação. No entanto, a análise dos dados não reflete melhorias dos indicadores educacionais, assim como em infraestrutura, que consubstanciem coesão social, territorial e governabilidade. Questiona-se qual o papel das ações públicas municipais no direcionamento de iniciativas que visem o desenvolvimento local e regional.

Somam-se a isso as falhas do sistema educacional brasileiro, que dificultam a adequação de soluções às peculiaridades regionais, locais e mesmo as de cada bairro e de cada escola. Schwartzman et al. (1993) destaca que os problemas organizacionais são agravados pela instabilidade administrativa dos poderes públicos. No nível estadual e municipal, a eleição de novos governadores e prefeitos tende a levar ao poder partidos que estavam na oposição, o que promove o abandono de iniciativas anteriores. Por isto, todo o sistema se ressente da ausência de medidas de mais longo alcance que possam trazer correções cumulativas.

Em parte os resultados encontrados revelam que, apesar das melhorias da arrecadação fiscal do município, as conduções das politicas locais não consolidam o desenvolvimento local. Sendo assim, é possível perceber a dificuldade do município em levar em conta as questões do Desenvolvimento Territorial Sustentável. Os resultados da pesquisa indicam que parte dos problemas pode ser explicada pela pouca participação da sociedade civil local nos processos decisórios e deliberativos da esfera pública. A autonomia financeira do munícipio melhorou com as inversões de impostos decorrentes da implantação dos GPIs, no entanto, a prestação de contas é pouco transparente, sendo que ano a ano os dados são apresentados de modo diferente. Em suma, os investimentos em educação não seguem um modelo de inclusão social e de preparo da população local para as 
transformações estruturais no território. Esta mesma situação poderá ser replicada em estudos mais detalhados sobre bem estar, meio ambiente, mobilidade, entre outros aspectos inerentes ao desenvolvimento territorial sustentável.

\section{Referências}

ATLAS BRASIL. Programa das Nações Unidas para o Desenvolvimento; Instituto de Pesquisa Econômica Aplicada; Fundação João Pinheiro. Atlas do Desenvolvimento Humano no Brasil 2013. Disponível em: <http://www.atlasbrasil.org.br/2013>. Acesso em: 6 ago. 2013.

BUENO, J. Com a instalação da TKCSA, abre-se caminho para instalação de um polo metal-mecânico naquela área. Rio de Janeiro: Jornal dos Economistas, n. 239, junho de 2009.

FERRAZ, Lucimar de Andrade Macedo. Análise da atuação dos Conselhos Comunitários enquanto instrumento de acompanhamento e participação na implementação do Plano Diretor de Desenvolvimento Sustentável do Município de Itaguaí - RJ. Dissertação PPGDT/UFRRJ, 2014.

FIRJAN - Federação das Indústrias do Estado do Rio de Janeiro. Índice FIRJAN de Gestão Fiscal. Disponível em: <http://www.firjan.org.br>. Acesso em: 1 ago. 2014.

IBGE - Instituto Brasileiro de geografia e Estatística. IBGE Cidades. Disponível em: <http://cidades.ibge.gov.br/xtras/home.php>. Acesso em: 27 ago. 2014.

PERICO, R. E. Identidade e território no Brasil. Brasília: Instituto Interamericano de Cooperação para a Agricultura, 2009.

PREFEITURA. Prefeitura Municipal de Itaguaí. Contas Públicas. Disponível em: <http://www.prefeituraitaguai.com.br/novo_site/index.php>. Acesso em: 13 jun. 2014.

SCHWARTZMAN, Simon et al. A Educação no Brasil em uma perspectiva de transformação. Universidade de são Paulo, Junho de 1993.

TENÓRIO, F. G. Tem razão a administração? 3. ed. Ijuí: Editora da Unijuí, 2008a. 
. Um espectro ronda o terceiro setor, o espectro do mercado. 3. ed. Ijuí: Editora da Unijuí, 2008b

VAINER, Carlos Bernardo. A escala do poder e o poder das escalas: O que pode o poder local? Revista Brasileira de Estudos Urbanos e Regionais, Rio de Janeiro IPPUR/UFRJ, 2001.

VILLELA, L. E; GUEDES, C. A. M; SANTANA, J, S e BRITTO, E, B, R. Crescimento econômico versus gestão social e Desenvolvimento territorial sustentável. Análise dos Impactos de Megaempreendimentos nos Municípios de Macaé-RJ e de Itaguaí-RJ. Desenvolvimento em Questão, ano 10, n. 21, set./dez. 2012.

Endereço para correspondência:

LamounierErthal Villela - lamounier.erthal@gmail.com

Rod. Br 465, Km 7

23890-000 Seropédica/RJ, Brasil

Marcelo de Oliveira Vidal-celovidal@hotmail.com

Rod. Br 465, Km 7

23890-000 Seropédica/RJ, Brasil 